\title{
A análise da Vulnerabilidade Ambiental como subsídio para a gestão da Lagoa do Bacuri, Maranhão - Brasil.
}

\section{Analysis of environmental vulnerability as a subsidy for the management of Lagoa do Bacuri, Maranhao - Brazil .}

\author{
RABELO $^{1}$, T. O.; SOUZA ${ }^{2}$, U. D.V.; FEITOSA ${ }^{3}$, A. C.
}

thiarageo@hotmail.com;

\begin{abstract}
Resumo
Os estudos geográficos voltados para a vulnerabilidade ambiental, com auxílio das geotecnologias, colaboram para simulação e monitoramento de áreas em situação de risco ambiental, possibilitando a articulação de ações de planejamento e gestão. $\mathrm{O}$ estudo da vulnerabilidade ambiental da lagoa do Bacuri, situada na porção nordeste do Estado do Maranhão, se constitui como base para o planejamento das formas de uso da terra apresentando graus diferenciados de vulnerabilidade, definidos a partir da associação de atributos naturais e humanos da área de estudo e da utilização da análise de multicritérios que permitiram um prognóstico para a diminuição de riscos relativos a inundações, déficits hídricos ou processos erosivos, entre outros. Os estudos realizados indicam que as áreas de maior risco ambiental são constituídas por sedimentos geológicos mais grosseiros com matriz arenoargilosa e solos situados em relevos com topos planos ou levemente ondulados com cotas altimétricas variadas, constituindo áreas de vertentes com cobertura vegetação de médio porte típica da região do semi-árido.
\end{abstract}

Palavras-chave: Vulnerabilidade, Planejamento Ambiental, Lagoa do Bacuri.

\begin{abstract}
Geographic studies focused on environmental vulnerability, with the help of geotechnology, collaborate for simulation and monitoring areas at environmental risk, enabling the articulation of planning and management actions. The study of environmental vulnerability of Bacuri lagoon, located in the northeastern area of the state of Maranhão, , is constituted as a basis for the planning of land use forms showing different degrees of vulnerability, defined from the combination of natural and human features of the study area and from the use of advanced analysis which enabled a forecast to decrease risks related to floods, water deficits or erosion, among others. Studies indicate that the areas of greatest environmental risk consist of coarser geological sediments with sandy-clay matrix and soils located in reliefs with flat tops or slightly wavy with varying elevations, constituting areas strands with typical medium cover vegetation coverage of the semi-arid region.
\end{abstract}

Keywords: Vulnerability, Environmental Planning, Pond Bacuri.

\section{INTRODUÇÃO}

A implantação de medidas de planejamento para a diminuição de riscos ambientais com vistas na melhoria da qualidade de vida a partir do uso sustentável dos recursos naturais está em voga na atualidade, posto que o homem é um dos principais agentes intensificadores das alterações ambientais.

Este cenário pode ser observado em todo Brasil, e tem se destacado na área de abrangência da lagoa do Bacuri, no nordeste do Estado do Maranhão. A lagoa está inserida no bioma Cerrado e conta com uma dinâmica ambiental atrelada à sazonalidade climática, condicionantes geológicos e geomorfológicos que atuam diretamente na distribuição de cursos d'água e na presença de solos 
quimicamente pobres com vegetação de médio porte nas áreas de base e topo de vertentes e palmáceas nas áreas mais próximas ao corpo hídrico.

As comunidades que habitam a área de entorno da lagoa do Bacuri se utilizam diretamente dos recursos do ecossistema, mas as limitações impostas por sua indisponibilidade condicionam o processo de produção espacial que está ligado às atividades agrícolas familiares e a pesca, ambas praticadas com o emprego de técnicas tradicionais.

É importante destacar as atividades ligadas à agricultura mecanizada, principalmente a monocultura da soja, que tem avançado em direção a área da lagoa. Os diferentes tipos de usos e as características naturais da área e de cobertura da terra proporcionam ao ambiente da lagoa alterações nos níveis de vulnerabilidade ambiental. O eficaz planejamento é essencial para o uso sustentável dos recursos naturais.

As inferências geográficas realizadas a partir do uso das geotecnologias permitem resultados que auxiliam no diagnóstico de áreas vulneráveis a riscos ambientais, tendo por base a avaliação do ambiente de forma integrada, compatibilizando suas especificidades naturais. Como objetivo da pesquisa, procurou-se identificar os níveis de vulnerabilidade ambiental da área de entorno da lagoa do Bacuri, a partir da aplicação do Índice de Vulnerabilidade Ambiental (IVA), como subsídio para o planejamento e gestão ambiental da área.

\section{METODOLOGIA}

A identificação da vulnerabilidade ambiental da lagoa do Bacuri foi feita a partir da aplicação e adaptação da metodologia proposta por Crepanni et al (2001), utilizando a sobreposição de dados temáticos e fundamentada na análise de multicritérios (CAMPOS, 2011) permitindo a comparação de vários critérios e levando a uma tomada de decisão ponderada.

Para o alcance dos resultados desta pesquisa foram seguidos os seguintes procedimentos metodológicos:

- - Obtenção de dados referentes a fatores físicos da área de abrangência da Lagoa do Bacuri como geologia, geomorfologia, pedologia e vegetação disponíveis no Banco de dados do CPRM (2010), IBGE (2010) e do MMA (2001);

- - Imagens do satélite Landsat 5 TM do ano de1994 e Landsat 8 TM 2013 disponibilizadas no Catálogo de Imagens do Instituto Nacional de Pesquisas Espaciais para a elaboração do mapa de uso e ocupação;

- - Dados obtidos a partir do mosaico SRTM elaborado por MIRANDA (2004) para produção do mapa de declividade; 
- - Utilização de um software de processamento digital de imagens de satélite para tratamento de imagens, segmentação e classificação supervisionada e produção do mapa de uso e ocupação;

- - Utilização de software de geoprocessamento para a conversão de vetores em raster, atribuição de pesos, reclassificação de valores, cálculo do Índice de Vulnerabilidade Ambiental e para produção do layout final do mapa de vulnerabilidade ambiental.

- - Representação cartográfica, análise e interpretação dos dados relativos à área estudada e à temática abordada;

Durante a pesquisa foram realizadas jornadas de campo para a observação da paisagem em diferentes pontos para validação de dados e utilização de recursos iconográficos como fotografias; visita a órgãos, secretarias municipais e cooperativas para a obtenção de dados referentes à agricultura, pesca, saúde, transporte, economia, dentre outros aspectos.

\section{RESULTADOS E DISCUSSÃO}

\subsection{A Lagoa do Bacuri: localização geográfica e aspectos geoambientais}

A lagoa do Bacuri, está situada na porção nordeste do estado do Maranhão, a leste do Rio Parnaíba (Figura 01). A lagoa possui a maior parte de sua área no município de Magalhães de Almeidae uma porção menor no município de São Bernardo, inseridos na mesorregião leste maranhense e na microrregião do Baixo Parnaíba.

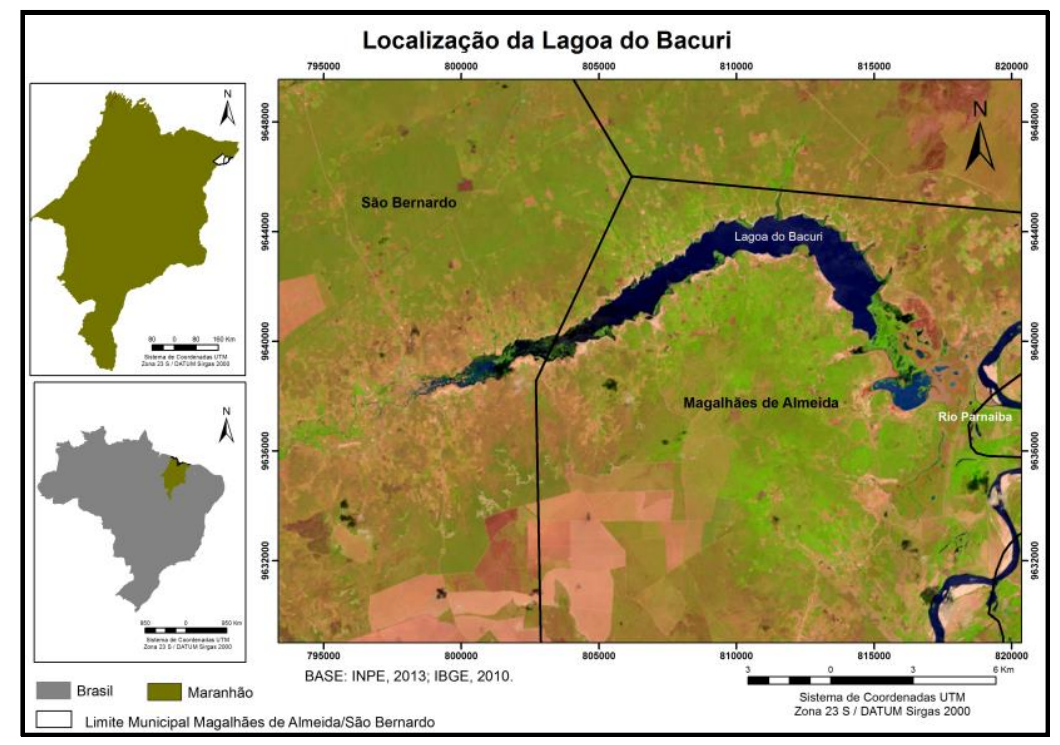

Figura 01: Localização da Lagoa do Bacuri. Fonte: Elaborado pelos autores.

De acordo com Almeida Jr. (2012) na região da lagoa do Bacuri, a formação geológica é do tipo arenitos e leitos de argila e é pertencente à bacia sedimentar do Maranhão, a qual se 
identifica por ser a região deposicional associada ao rio Parnaíba. Quanto a geomorfologia na área se destaca principalmente a planície fluvial, e relevos dissecados associados a áreas de tabuleiros.

De acordo com a EMBRAPA, (1986), o município de Magalhães de Almeida o município apresenta predomínio latossolos amarelos, solos podzólicos vermelho-amarelos eutróficos, sendo estes mais próximos da área da lagoa do Bacuri, e solos aluviais e as areias quartzosas. Feitosa e Trovão (2006) descrevem para a região clima do tipo sub-úmido e sub-úmido seco, com temperatura média anual superior a $27^{\circ} \mathrm{C}$ e precipitação média anual entre $1200 \mathrm{~mm}$ a $2000 \mathrm{~mm}$.

No que se refere a hidrografia, a lagoa do Bacuri recebe água do rio Buriti, que nasce no município de São Bernardo e de pequenos cursos d'água que deságuam em suas margens na forma de brejos e banhados, característicos da região. Sobre a vegetação, o corpo hídrico está situado em uma área de dunas e restingas, segundo Feitosa e Trovão (2006). Além do cerrado, na região de entorno da lagoa do Bacuri é possível identificar manchas de caatinga que aparecem nas encostas e nos topos dos tabuleiro. Na paisagem local, aparecem palmáceas como a carnaúba (Copernicia prunifera Miller),geralmente em locais mais próximos ao corpo hídrico.

Quanto as principais atividades humanas da área, destaca-se a agricultura familiar, que é desenvolvida pela maioria da população das comunidades próximos a lagoa, e o aumento gradativo das áreas utilizadas para a agricultura mecanizada, principalmente para a monocultura da soja, que vem se expandindo nos últimos anos na região.

O extrativismo vegetal, principalmente da palha da carnaúba, e a produção de carvão vegetal também se configuram como atividades econômicas do local, por parte das comunidades. A pesca artesanal é muito praticada pelos moradores da área. Em alguns locais observa-se o uso de tanques-redes, para criatórios de peixes.

\subsection{Aplicação do Índice de Vulnerabilidade Ambiental na área de entorno da Lagoa do Bacuri}

Siché et al (2007) afirmam que um índice revela um estado de um sistema ou fenômeno constituindo um valor agregado final de um procedimento de cálculo onde são utilizadas mais de uma variável. Para as análises referentes a vulnerabilidades, são necessárias as associações de vários atributos relevantes em uma área para o alcance de resultados que possam subsidiar medidas de planejamento e gestão.

As variáveis escolhidas para aplicação do Índice de Vulnerabilidade Ambiental desta análise estão associadas a características intrínsecas da área, como o nível de elevação do terreno, as classes predominantes de solo, ao substrato rochoso, ao tipo de relevo da área, as tipologias vegetais e ao uso e cobertura da terra que no cálculo do índice resultam da média aritmética da associação entre valores individuais de cada tema. 
Nesta pesquisa, foram levadas em consideração as características naturais da área e os pesos atribuídos as variáveis foram redefinidos de acordo com seus atributos e a partir da associação de elementos como geologia, declividade, pedologia, vegetação, uso da terra que compõe as Unidades Territoriais Básicas, conforme sugerido por Crepani et al (2001), que contribuíram na definição do peso de influência de cada variável para a elaboração do IVA (Quadro 01).

Quadro 01: Atributos considerados para o cálculo do IVA da lagoa do Bacuri. Fonte: Adaptado de Rabelo (2015).

\begin{tabular}{|c|c|c|c|}
\hline \multicolumn{4}{|c|}{ Quadro de Atributos para o IVA } \\
\hline Classes & Atributos & Peso & Influência (\%) \\
\hline \multirow[t]{4}{*}{ Geologia } & Formação Barreiras & 3 & \multirow{4}{*}{$10 \%$} \\
\hline & Formação Longá & 3 & \\
\hline & Depósitos eólicos continentais antigos & 2 & \\
\hline & Depósitos aluvionares & 2 & \\
\hline \multirow{4}{*}{ Declividade (\%) } & 7,45 & 1 & \multirow{4}{*}{$20 \%$} \\
\hline & 15,29 & 1 & \\
\hline & 25,49 & 2 & \\
\hline & 42,74 & 3 & \\
\hline \multirow{4}{*}{ Altimetria } & $10-50$ & 1 & \multirow{4}{*}{$15 \%$} \\
\hline & $50-70$ & 1 & \\
\hline & $70-90$ & 2 & \\
\hline & $90-110$ & 2 & \\
\hline \multirow{5}{*}{ Pedologia } & Latossolos amarelo distrófico & 1 & \multirow{5}{*}{$15 \%$} \\
\hline & Argissolo vermelho-amarelo distrófico & 2 & \\
\hline & Organossolo háplico sáprico & 3 & \\
\hline & Plintossolo háplico distrófico & 3 & \\
\hline & Plintossolo pétrico concrecionário distrpofico & 3 & \\
\hline \multirow{3}{*}{ Vegetação } & Savana/Floresta Estacional & 2 & \multirow[b]{3}{*}{$10 \%$} \\
\hline & Savana/Floresta Estépica & 3 & \\
\hline & Savana/Savana estépica/ Floresta Estacional & 3 & \\
\hline \multirow{7}{*}{ Uso e Cobertura } & Água & 1 & \multirow{7}{*}{$30 \%$} \\
\hline & Área Úmida & 1 & \\
\hline & Vegetação Arbórea & 2 & \\
\hline & Vegetação Arbustiva & 3 & \\
\hline & Área de Cultivo & 3 & \\
\hline & Solo Exposto & 3 & \\
\hline & Área de queimada & 3 & \\
\hline
\end{tabular}

A elaboração do Índice de Vulnerabilidade Ambiental da área de entorno da lagoa do Bacuri está separada em cinco classes com graus diferenciados que variam entre 1 a 3 , segundo a metodologia adaptada de Crepani et al (2001) que foram divididos em: Muito Alto, Alto, Médio, Baixo e Muito Baixo; onde a menor classe apresenta 1,4 e a maior classe indica 3 no ano de 1994; e no ano de 2013 o índice apresentou em sua menor classe o valor de 1,2 e na maior classe indicou 2,8 .

A diferenciação na porcentagem de influência para o resultado final do grau de vulnerabilidade na área foi feita de acordo com os atributos mais determinantes para sua ocorrência (Quadro 02), neste caso aspectos geomorfológicos como declividade e altimetria, tipos de solo e uso 
e cobertura da terra; que estão associados a tipologia de sedimentos que compõem o solo e a sua permeabilidade e porosidade; assim como as formas de relevo mais planas ou onduladas que se relaciona com a aptidão agrícola e a riscos ambientais como enchentes.

Quadro 02: Características das áreas vulneráveis. Fonte: Elaborado pelos autores.

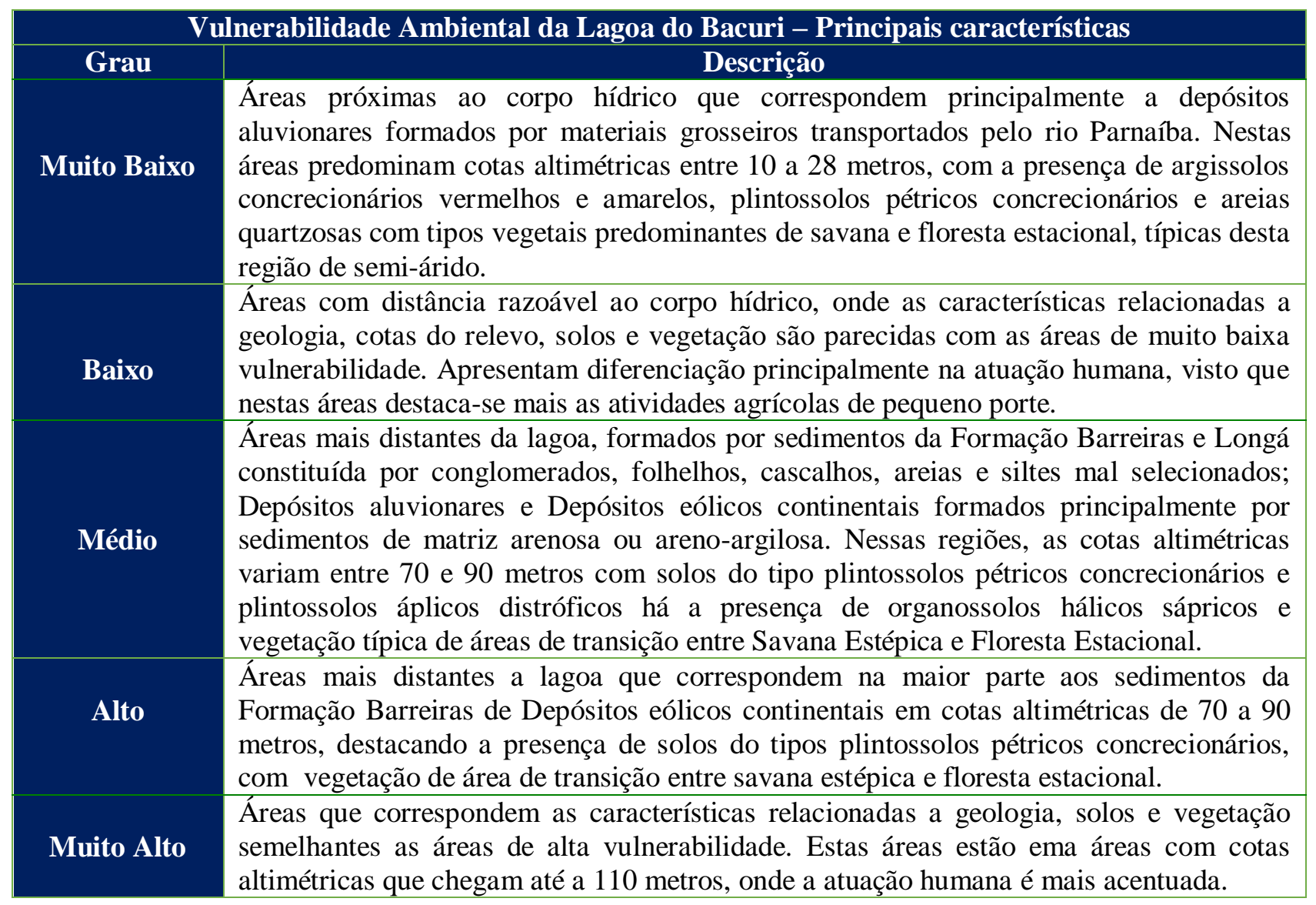

A partir dos diferentes graus de vulnerabilidade definidos a partir da aplicação do índice na área de abrangência da lagoa do Bacuri, é possível observar a espacialização dos valores que mostram o aumento gradativo entre aos anos de 1994 e a 2013, principalmente das áreas de média e alta vulnerabilidade ambiental.

As áreas de vulnerabilidade muito baixa e baixa possuem características naturais semelhantes, sendo necessário destacar as diferenças na atuação humana, que onde foram identificados graus de vulnerabilidade baixo a atuação humana é mais expressiva, destacando-se as áreas de pequenas produções agrícolas, que no ano de 1994 eram menos acentuadas se comparadas ao ano de 2013 (Figura 03 e 04), o que segundo Rabelo (2015), contribuiu para que parte destas áreas fossem, em 2013, consideradas com grau médio de vulnerabilidade ambiental. 


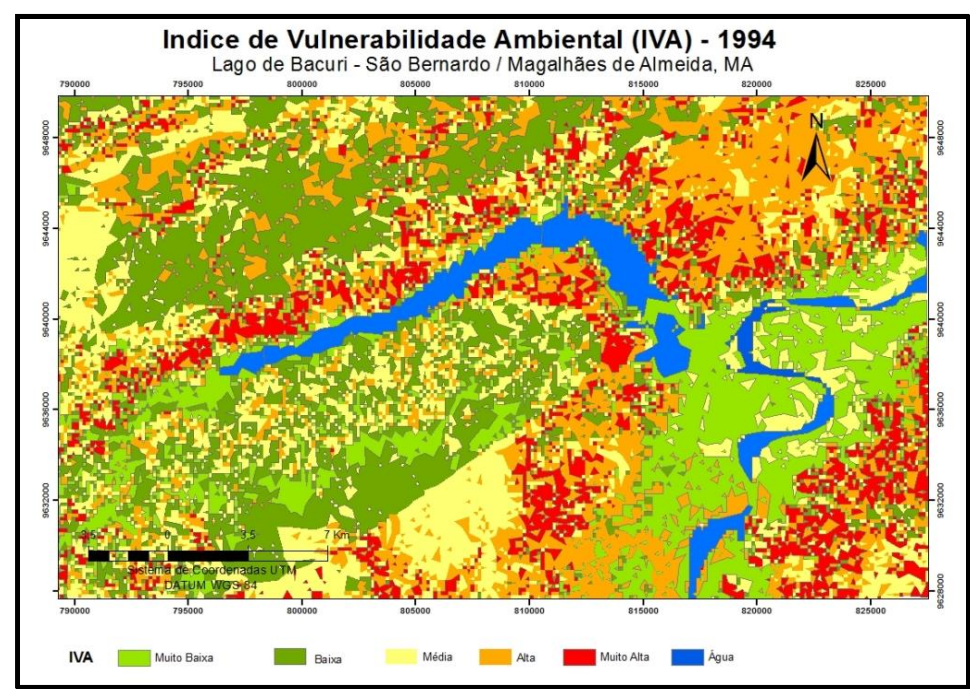

Figura 03: IVA da Lagoa do Bacuri, 1994. Fonte: Rabelo, 2015

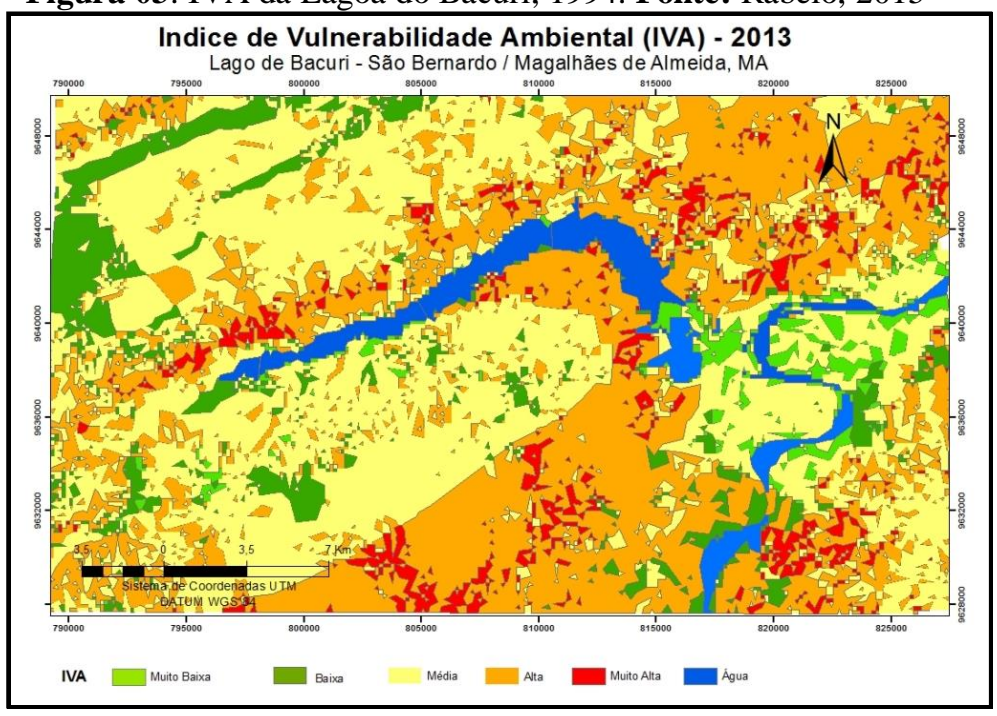

Figura 04: IVA da Lagoa do Bacuri, 2013. Fonte: Rabelo, 2015.

É importante destacar que parte das áreas de baixo grau de vulnerabilidade também se converteram em regiões vulneráveis de médio grau, visto que nestes locais predominam principalmente solos do tipo argissolos vermelho amarelo concrecionários e plintossolos pétricos concrecionários que possuem diferenças texturais que dificultam a infiltração da água tornando-o suscetível a processos erosivos.

Aspectos relacionados ao uso e a cobertura da terra também apresentaram mudanças acentuadas nestas áreas, influenciando nesta alteração da vulnerabilidade dos graus médio e baixo entre 1994 e 2013, visto que as extensões de solo exposto e o número de áreas de cultivo aumentaram (Tabela 01), consideravelmente, na região no último ano.

Tabela 01: Áreas de uso e cobertura da terra - lagoa do Bacuri. Fonte: Elaborada pelos autores.

\begin{tabular}{|c|c|c|}
\hline Classes & $\mathbf{1 9 9 4}\left(\mathbf{K m}^{\mathbf{2}}\right)$ & $\mathbf{2 0 1 3}\left(\mathbf{K m}^{\mathbf{2}}\right)$ \\
\hline Água & 27,50 & 25,71 \\
\hline Vegetação Arbórea & 625,36 & 259,15 \\
\hline Vegetação Arbustiva & 561,36 & 279,28 \\
\hline
\end{tabular}




\begin{tabular}{|c|c|c|}
\hline Áreas Úmidas & 189,04 & 48,97 \\
\hline Solo exposto & 193,90 & 126,25 \\
\hline Áreas de Cultivo & 92,68 & 124,88 \\
\hline Queimadas & ------ & 47,0 \\
\hline
\end{tabular}

As áreas indicadas com graus médios de vulnerabilidade estão relacionados principalmente a cotas altimétricas que variam entre 70 e 90 metros e onde predominam áreas de vegetação de transição entre o cerrado e a caatinga, que constituem uma vegetação de médio porte.

Rabelo (2015), destaca a ocorrência de plintossolos pétricos concrecionários e plintossolos áplicos distróficos e a presença de organossolos hálicos sápricos que apresentam horizontes com constituição orgânica e fertilidade natural alta, o que justifica a aumento das áreas de cultivo nestes locais e consequentemente a elevação das áreas de baixo grau de vulnerabilidade em 1994 para áreas de médio grau no ano de 2013 (Tabela 02).

Tabela 02: Áreas por km² dos graus de vulnerabilidade na lagoa do Bacuri. Fonte: adaptado de Rabelo, 2015.

\begin{tabular}{|c|c|c|c|}
\hline \multicolumn{4}{|c|}{ Áreas de Vulnerabilidade Ambiental $\left(\mathbf{k m}^{\mathbf{2}}\right)$} \\
\hline Grau & $\mathbf{1 9 9 4}$ & $\mathbf{2 0 1 3}$ & Diferença \\
\hline Muito Baixo & 134,2 & 23,28 & 110,74 \\
\hline Baixo & 209,40 & 68,81 & 140,59 \\
\hline Médio & 193,27 & 364,11 & 170,84 \\
\hline Alto & 201,26 & 325,61 & 124,25 \\
\hline Muito Alto & 104,61 & 43,28 & 61,33 \\
\hline
\end{tabular}

No ano de 2013, foi identificado o visível aumento das áreas com alto grau de vulnerabilidade, devido às ações humanas mais intensas, onde foi possível identificar regiões de queimadas, apresentando registro de 211 focos de áreas queimadas no município de Magalhães de Almeida neste ano, segundo o programa de Monitoramento de Queimadas e Incêndios do Instituto de Estudos e Pesquisas Espaciais.

Estas queimadas estão relacionadas principalmente a áreas que correspondem à plantação de soja nesta parte do Estado, plantação de eucalipto, em menor escala, e a produção industrial de carvão. As poucas áreas identificadas com alto grau de vulnerabilidade ambiental, na lagoa, estão dispostas em cotas altimétricas que chegam até 110 metros e onde foram identificadas as áreas de maior atuação humana.

O aumento, dessas médias relacionados ao alto grau de vulnerabilidade se deve principalmente ao crescimento gradativo da agricultura mecanizada e nas culturas permanentes como a monocultura da soja e o plantio do eucalipto que embora seja mais recente na região, se situa em áreas próximas a lagoa e está ganhando grandes proporções na área, o que pode futuramente comprometer a disponibilidade hídrica da lagoa, visto que este tipo de plantação possui acentuada exigência hídrica (RABELO, 2015).

A maior parte das comunidades localizadas próximos a lagoa estão em áreas de média e alta vulnerabilidade, fato que deve ser considerado posto que são locais mais propensos ao desgaste 
do solo e a futuros cenários de degradação do ambiente. Estas áreas, por conta das suas características naturais, estão sendo cada vez mais ocupadas por grandes áreas de cultivo devido a sua localização em relação à lagoa.

Devido ao gradativo cenário, de aumento de ocupações humanas e principalmente aumento de áreas destinadas a agricultura mecanizada fazem com que várias famílias se sintam pressionadas a vender suas propriedades para os grandes agricultores que estão chegando na região, realidade que em alguns casos já ocorre em áreas próximas a lagoa do Bacuri e vem acontecendo em outros municípios vizinhos a Magalhães de Almeida e São Bernardo.

\section{CONSIDERAÇÕES FINAIS}

A análise geográfica é uma importante ferramenta para a compreensão do espaço e para o planejamento do ambiente, visto que considera a relação entre o homem e a natureza como essencial para suas pesquisas. Desta forma, trabalhar com a análise integrada de elementos para a identificação de áreas vulneráveis, é essencial para pensar o planejamento e gestão de uma área.

Como ferramentas que auxiliem na aplicação de metodologias voltadas para os estudos de vulnerabilidades, destacamos as geotecnologias, que contribuem para a simulação da integração e espacialização de cenários de vulnerabilidade. Sendo importante, relacionar tantos as características naturais quanto as ações humanas que podem vir a interferir na dinâmica natural do ambiente.

O Índice de Vulnerabilidade Ambiental da área de entorno da lagoa do Bacuri, a partir da associação destas características, apresenta as áreas com graus mais elevados de vulnerabilidades constituídas por sedimentos geológicos mais grosseiros com matriz areno-argilosa e solos que ocorrem em relevos mais planos ou levemente ondulados com cotas altimétricas variam entre 70 e 90 metros e vegetação de médio porte típica da região do semi-árido.

Os valores limiares entre as maiores classes diminuíram, porém é necessário levar em consideração que não houve de fato uma diminuição, mas uma alteração na dinâmica ambiental da área levando a que as classes que em 1994 foram consideradas com graus muito altos de vulnerabilidade passassem a apresentar graus médios e altos. Não havendo de fato uma mudança significativa na dinâmica natural da área, mas sim na atuação e interferência humana no local.

Em quase vinte anos, foi possível observar diferenças nítidas trazidas pela intensificação da ação humana, atualmente não só ligada a atividades rudimentares de uso dos recursos naturais, mas também a técnicas e tecnologias agrícolas mais recentes, vinculadas a monocultura da soja, voltada para a agroexportação. O IVA permite que a partir das vulnerabilidades de uma área planejar as formas de uso e ocupação da terra. 
A compreensão da vulnerabilidade ambiental da lagoa do Bacuri proporciona o maior conhecimento das principais fragilidades da área a partir dos seus aspectos naturais e das principais ações humanas próximas a lagoa. Constituindo uma importante fonte para estudos posteriores e subsídio para o planejamento de futuras formas de uso e ocupação da área e atenuação de desastres ambientais inundações, déficits hídricos ou intensos processos erosivos.

\section{REFERÊNCIAS}

ALMEIDA JR. E.S. Lagoa do Bacuri, Magalhães de Almeida-MA: interrelações das comunidades do entorno com o ecossistema sob ótica da sustentabilidade. Dissertação apresentada ao Programa de Pós-Graduação em Sustentabilidade e Ecossistema da Universidade Federal do Maranhão. 2012. 107 p.

BRASIL. MMA. Ministério do Meio Ambiente. Plataforma I3GEO. Cobertura Vegetal do Brasil. Disponível em http://www.mma.gov.br/governancaambiental/ geoprocessamento/download-doi3geo. 2002. Acesso em: 14/07/14.

CAMPOS, M.B.A. Métodos multicritérios que envolvem a tomada de Decisão. Monografia apresentada ao curso de especialização em Matemática do Departamento de Matemática do Instituto de Ciências Exatas da Universidade Federal de Minas Gerais. 2011. 51 p.

CPRM. Companhia de Pesquisas de Recursos Minerais/ Serviço geológico do Brasil. Mapas Geológicos Estaduais. Maranhão. 2010. Disponível em: http://geobank.cprm.gov.br/pls/publico/geobank.download.downloadVetoriais?. Acesso em: 10/07/14.

CREPANI, E. et al. (2001). Sensoriamento Remoto e Geoprocessamento aplicados ao Zoneamento Ecológico-Econômico e ao ordenamento territorial. INPE. São José dos Campos. 2001. 103 p. Disponível em: http://www.dsr.inpe.br/laf/sap/artigos/CrepaneEtAl.pdf. Acesso em: $10 / 06 / 2015$.

EMBRAPA. Empresa Brasileira de Pesquisa Agropecuária. Solos do Nordeste. Maranhão. 1986. Disponível em: http://www.uep.cnps.embrapa.br/solos/index.php?link=ma. Acesso em: 15/07/2015.

FEITOSA, A. C.; TROVÃO, J. R. Atlas Escolar do Maranhão: Espaço Geo-histórico e Cultural. Editora Grafset, 2006. 201 pg.

IBGE. Instituto Brasileiro de Geografia e Estatística. Geociências. Pedologia do Brasil. IBGE. Rio de Janeiro, 2010. Disponível em: http://www.mapas.ibge.gov.br/tematicos/solos . Acesso em: $17 / 07 / 2015$.

INPE. Instituto Nacional de Pesquisas Espaciais. Catálogo de Imagens. São José dos Campos. 2013. Disponível em: http://www.dgi.inpe.br/CDSR/. Acesso em: 13/07/2015.

INPE. Instituto Nacional de Pesquisas Espaciais. Programa de Monitoramento de Queimadas e Incêndios. Disponível em: http://www.dpi.inpe.br/proarco/bdqueimadas/. 2013. Acesso em: 15/08/14. 
MIRANDA, E. E. de; COUTINHO, A. C. (Coord.). Brasil Visto do Espaço. Campinas: Embrapa Monitoramento por Satélite. 2004. Disponível em: <http://www.cdbrasil.cnpm.embrapa.br>. Acesso em: 15/08/2014.

RABELO, T. O.; SOUZA, U. D. V. e FEITOSA, A. C. Indicadores de Sustentabilidade Ambiental para o turismo na Lagoa do Bacuri, Magalhães de Almeida - MA. II Congresso Nacional de Educação Ambiental e VII Simpósio Nacional de Turismo Sertanejo. João Pessoa. 2014. $12 \mathrm{p}$.

RABELO, T.O. O Índice de Vulnerabilidade Ambiental (IVA) como instrumento para o planejamento ambiental da lagoa do Bacuri - MA. Monografia apresentada ao curso de Geografia da Universidade Federal do Maranhão para obtenção de grau de bacharel e licenciatura em Geografia. UFMA. 2015. 62 p.

SICHÉ. R. et al. Índices Versus Indicadores: precisões conceituais na discussão da sustentabilidade de países. Revista Ambiente \& Sociedade. Vol. X. № 2. 2007. 1-12 p.

Recebido em: 14/08/2016

Aceito para publicação em: 01/10/2016 